\title{
Análise comparada da estrutura e desempenho dos bancos centrais de três países da América latina através de um modelo de vetor auto-regressivo (VAR/VEC)
}

\section{Comparative Analysis of the Structure and Performance of Central Banks of Selected Countries in Latin America through Auto-Regressive Vector Model (VAR/VEC)}

\section{Sílvia Letícia Bampi}

Mestre (a) em Economia pelo Programa de Pós-Graduação em Economia (PPGE) da Universidade do Vale do Rio dos Sinos (UNISINOS), Brasil https://orcid.org/0000-0003-2340-8386

lety_silvia@hotmail.com

\section{Kim Ellwanger}

Mestre em Economia pelo Programa de Pós-Graduação em Economia (PPGE) da Universidade do Vale do Rio dos Sinos (UNISINOS), Brasil kim_nh@hotmail.com

\section{Divanildo Triches}

Doutor em Economia pela Universidade Federal do Rio Grande do Sul. Pesquisador e professor no Programa de Pós-Graduação em Economia da Universidade do Vale do Rio dos Sinos, PPGE/UNI-

SINOS, Brasil

https://orcid.org/0000-0001-6974-3310 divanildo@pq.cnpq.bredivanildot@unisinos.br

Fecha de recepción: 15 de mayo de 2017 Fecha de aceptación: 01 de noviembre de 2017

Sugerencia de citación: Bampi, S.L., Ellwanger. K. y Triches, D. (2018). Análise comparada da estrutura e desempenho dos bancos centrais de três países da América latina através de um modelo de vetor auto-regressivo (VAR/VEC).tiempo\&economía, 5(1), 101-122 doi: http://dx.doi.org/10.21789/24222704.1277 


\section{RESUMO}

Esse artigo tem como objetivo analisar o desempenho dos Bancos Centrais (BC) de três países da América Latina, verificando a sua política de atuação e identificando os modelos monetários que obtiveram um melhor desempenho econômico frente aos diversos ciclos no período de 2000 a 2014. Estimou-se um modelo de Vetor Auto-regressivo (VAR/VEC) onde os coeficientes evidenciaram que para Brasil e Chile, as variáveis comumente utilizadas para se avaliar a interferência dos $B C$, tiveram influência significativa nas demais variáveis da economia consideras no estudo. Para o México, no entanto, essas variáveis não apresentaram significância. As evoluções financeiras atreladas a globalização e a abertura comercial restringiram a atuação dos agentes reguladores promovendo mudanças com relação a atuação destes para o futuro. Desta forma, a redução de incertezas políticas e econômicas, relacionada a maior inserção dos países no sistema internacional, refletem mudanças nas estratégias dos bancos centrais.

Palavras-chave: Bancos Centrais, Desempenho, Dinâmica Macroeconômica, Vetor Auto-regressivo, história econômica

Códigos JEL: E43, E44, C58.

\section{ABSTRACT}

The article's objective is to analyze the performance of the Central Banks of three Latin American countries, verifying their operating policy and identifying the monetary models that have obtained the best economic performance between 2000 and 2014. A Vector Autoregressive Model was estimated in which the coefficients evidenced that for Brazil and Chile, the variables had a significant influence in the remaining variables of the economy. For Mexico, however, these variables were not significant. The financial innovations linked to globalization and trade liberalization have restricted the activities of regulating agents, promoting changes regarding the performance of the latter for the future. Thus, reduction of political and economic uncertainties, related to greater integration of countries in the international system, reflect changes in the strategies of central banks.

Keywords: Central Banks, Performance, Macroeconomic dynamic, Auto-Regressive Vector, Economic History

JEL Codes: N01, D63, R11, O47 


\section{Introdução}

A interdependência do Banco Central, seu grau de interação com o governo e os efeitos de seu desempenho nas economias têm sido objeto de ampla pesquisa na área econômica e financeira nas últimas cinco décadas. Crowe e Meade (2007) descreve que ocorreram enormes mudanças nos Bancos Centrais e em seus procedimentos operacionais tendo em vista ao ambiente de inflação generalizada que assolaram as economias mundiais ao longo das décadas de 1970 e 1980. Essa forma de atuação dos Bancos Centrais passou de uma meta ou controle de um determinado agregado monetário para o controle da taxa de juros de curto prazo. A partir dos anos de 1990, muitos países adotaram um sistema de meta de inflação.

Com despeito da temática da independência do Banco Central, Kydland e Prescott (1977), Barro e Gordon (1983), Rogoff (1985), Walsh (1995) e Cukierman (1996) mostraram que uma maior independência dessa instituição teria também maior probabilidade de estabelecer políticas monetárias que culminasse uma inflação mais baixa. Blinder et al. (2001), Faust e Svensson (2001) e Geraats (2002) apontaram que transparência e a comunicação e, portanto, a credibilidade dos Bancos Centrais são fatores cruciais que colaboram para melhorar a eficácia e o desempenho da política monetária.

Notadamente, o desenvolvimento dos Bancos Centrais no pós-segunda guerra teve como marco primordial a ser perseguido foi a estabilidade de preços. Segundo Cobham (2012), o contexto mundial antecedente a esse evento pairava por entre taxas de juros excepcionalmente baixas e proporções da dívida elevada, nesse cenário os bancos centrais eram tipicamente muito mais subordinados a seus governos. No momento que as taxas de câmbio foram fixadas por imposição do acordo de Bretton Woods, mudanças significativas foram inseridas no papel da política monetária em que a tornou incapaz de afetar a renda doméstica.

Contudo, a partir do processo de estagflação dos anos 1970 e o fraco desempenho econômico experimentado por alguns países e com inflação elevada na América Latina, o paradigma Keynesiano prevalecente de que a inflação favorece o crescimento foi completamente rompido e nos anos 1980 e 1990. A concepção dominante passou a ser de que a inflação retarda o crescimento e que dever ser combatida a qualquer custo pelos Bancos Centrais. Além disso, o os Bancos Centrais deveriam contribuiu para a manutenção da estabilidade financeira garantindo uma posição sólida aos bancos comerciais. Para isso, de acordo com a concepção de Jacomé (2015) a estabilidade monetária estaria associada a uma emissão de moeda condizente a uma regra próxima ao do sistema padrão-ouro, visando garantir uma taxa de câmbio estável e baixa inflação.

Dessa forma o objetivo do presente estudo é investigar a estrutura o desempenho dos Bancos Centrais de países selecionados da América Latina: Brasil, Chile e México, verificando a sua política de atuação e identificando os modelos monetários entre 2000 a 2014. A relevância do estudo justifica-se no fato que a atuação dos Bancos Centrais na economia dos países latino americanos tende a guiar a economia para uma expansão dada que sua atuação seja independente de interesses políticos, além de que a condução da política monetária desempenha papel fundamental na manutenção da estabilidade e alcance de níveis mais elevados de desenvolvimento de um país. 
O estudo está subdividido em cinco seções, além dessa introdução. A segunda seção traz uma breve revisão do papel dos Bancos Centrais no sistema financeiro internacional e descreve uma evolução histórica dos os Bancos Centrais dos países selecionados da América Latina o surgimento e a estrutura dos mesmos. A terceira seção destaca aspectos metodológicos e as definições das variáveis comumente mencionadas em estudos macroeconômicos. A quarta apresenta um comparativo entre a atuação deste nos diversos choques econômicos verificando sua atuação e desempenho através de um modelo de Vetor Auto-regressivo (VAR/VEC). Por fim, na quinta, encontram-se as conclusões.

\section{Bancos Centrais no contexto Internacional}

A propagação dos Bancos Centrais em âmbito internacional se constitui um fenômeno tipicamente do século xx. Antes disso, os bancos eram ligados aos governos possuíam o monopólio sobre a emissão de moeda. O Banco Central mais antigo é o da Suécia, o Riksbank que foi constituído em 1668, após foram criados os bancos da Inglaterra, em 1694, o Banco da França, em 1800, o Banco da Holanda, em 1814, o Banco Nacional da Áustria em 1817. Os Estados Unidos constituíram o Federal Reserve System com o papel de Banco Central, em 1914, por meio de uma lei sancionada em 1913. O Canada instituiu o Bank o Canadá em 1934. Na América Latina, a maioria dos Bancos Centrais iniciam suas operações a partir de 1920, conforme Liddle e Pita (2011). Crowe e Meade (2007) mostram que existiam, no início do século xx, apenas 18 Bancos Centrais. Já, em 1950, eram contabilizados 59 Bancos Centrais e, em 1990, o número de bancos centrais cresceu para 161.

Originalmente os Bancos Centrais eram instituições fechadas, fornecedores de crédito ao governo. Porém essa função sofreu profunda modificação com desenvolvimento do sistema financeiro e com mudança na economia, mas que tradicionalmente permaneceu consenso de que os Bancos Centrais possuem cinco importantes diretrizes, ou seja; i) conduzir a política monetária, inclusive atuando de emprestador de última instancia; ii) preservar a estabilidade do sistema financeiro; iii) supervisionar e regular os bancos; iv) conduzir o sistema de pagamento e de liquidação, e v) emitir e controlar a emissão de moeda.

Todavia, as evidências mostram que, de acordo com Arnone et al. (2007), Haan e Kooi (1997), Mangano (1998) e Oatley (1999) Bancos Centrais autônomos apresentas benefícios na condução da política macroeconômica. Dentre esses aspectos positivos estão taxas mais baixas de inflação, melhores condições para enfrentar ciclos econômicos, sistema financeiro mais estável, com menores custos reais na economia em termos de volatilidade de produto, taxa de desemprego, ou na redução do crescimento econômico. Essa concepção é compartilhada por Blinder (2010) e Arnone et al. (2007) que para eles a escolha da taxa básica de juros bem como das reservas bancárias dever ser determinada de forma independente, além de definir a estabilidade de preços como um dos principais objetivos e restringir empréstimos ao governo.

A transparência das operações dos Bancos Centrais na condução da política monetária é outro tema destacado na literatura. Dincer e Eichengreen (2007) abordam que essa transparência tende a ser maior em países com sistemas políticos estáveis e com maior grau de desen- 
volvimento no mercado financeiro. Uma comunicação mais eficiente com o mercado sobre os objetivos das políticas macroeconômicas e as informações sobre as condições econômicas tem o poder de aumentar o bem-estar social, uma vez que, com políticas mais previsíveis os agentes serão capazes de tomar decisões mais conscientes. A comunicação da política monetária afeta os mercados financeiros com extrema rapidez, diferentemente, os preços e a taxa de juros são influenciados de forma gradual. ${ }^{1}$

A crise financeira de 2007-2008 alterou a forma de atuação dos Bancos Centrais como argumenta Mishkin (2012). Por mais que o regime de metas de inflação em vigor em muitos países continue válido, há quatro áreas pelas quais houve mudança na condução da política monetária: (i) compromisso de evitar o surgimento de bolhas de crédito, (ii) políticas que vise a gerenciar as expectativas para manter a economia estável, (iii) gerenciamento de riscos para instabilidades financeiras, e (iv) tratar da dominância fiscal que se constitui um dos maiores problemas para inúmeras economias no século xxı. Assim para Mishkin (2012), a crise internacional acabou por revelar que alguns dos pressupostos básicos relacionados ao Banco Central não eram mais sustentáveis, exigindo uma grande reformulação do seu papel.

Nessa direção, para Jacomé (2015) a crise testou o grau de preparação dos Bancos Centrais latino-americanos em gerenciar grandes choques reais e financeiros. Essas instituições se revelaram capazes de adotar uma estratégia de comunicação oportuna aos mercados em que suas decisões políticas foram necessárias para preservar a liquidez.

\section{Formação e estrutura dos Bancos Centrais latinos americanos}

A desordem e anarquia monetária, em geral, dominavam o sistema financeiro da maioria dos países América Latina ao longo dos anos de 1880. Várias moedas distintas circulavam em todo o território nacional, as quais eram emitidas pelos bancos nacionais e pelos bancos provinciais e privados. Era também comum em alguns países como na Argentina o uso de moedas estrangeiras segundo Liddle e Pita (2011).

As crises externas conflitos entre os países e movimentos revoltosos internos foram fatores marcantes que requeriam gastos crescentes por parte dos governos central. Esses gastos eram financiados, via de regra, por meio de emissão de moeda ou por empréstimos bancários os quais se constituam novos ingredientes a instabilidade a todo o sistema monetário. A insolvência dos bancos, como ocorria quase todos os países, impunha graves dificuldades para manter a conversibilidade das moedas locais.

Desse modo, a criação dos Bancos Centrais foi uma experiência permeada de conflitos de grupos de interesse pelo controle do poder monetário tanto no que se refere aos bancos privados como outros segmentos econômicos, além de grave crise bancária. Em geral, a constituição de cada Banco Central tende a refletir as particularidades de seu país, além de reproduzir as razões teóricas e históricas gerais, que deram origem a essas instituições singulares

1 A comunicação do Banco Central pode ser definida como a divulgação de informações ao público, sobre questões relacionadas aos objetivos da política monetária, estratégias de sua execução, perspectivas e cenários macroeconômicos.

tiempo\&economía

Vol. 5 N. ${ }^{\circ} 1$ - Enero - Junio de 2018

p. 105 
como argumenta Corazza (2006). Apesar disso, criação de bancos centrais nos países da América Latina guardam uma grande similaridade no que se refere a dificuldade apresentada em gerar condições políticas adequadas para garantir a constituição de entidade responsável pela emissão monetária.

O processo formal de sua criação dos bancos centrais tende a ser muito longo e marcado por avanços e retrocessos. No México, a origem do Banco Central remonta ao império de Agustin Iturbide, com a criação do Gran Banco do Império Mexicano, portanto esse processo levou mais de cem anos. No Brasil, ocorreram nada menos que 20 anos, a partir da criação da Superintendência da Moeda e do Crédito (Sumoc), em 1945 ou mais de 60 anos desde a proposta inicial.

Os grandes interesses contrários à criação de um banco central tem sido, portanto uma regra, nos países da América Latina, em que as instituições bancárias públicas ou privadas estariam no centro do imbróglio monetário, fiscal e financeiro que perpassa longos períodos de nossa história. Por um lado, as relações históricas entre as autoridades monetárias e as autoridades fiscais sempre foram pouco transparentes, e seus canais de comunicação mantiveram-se mais ou menos ocultos. Por outro, as relações das autoridades monetárias e suas políticas com os bancos privados também nunca foram claramente definidas como mostra Corazza (2006) para o caso brasileiro.

Na América Latina, Bancos Centrais foram concebidos inicialmente para satisfazer três objetivos principais: (i) manter a estabilidade monetária; (ii) ajudar a preservar a estabilidade dos bancos; e (iii) financiar o governo em uma base limitada. Para Jacomé (2015), a estabilidade monetária resultaria de uma emissão de moeda associada com as regras do sistema padrão-ouro, visando garantir uma taxa de câmbio estável e baixa inflação, além de manter a estabilidade financeira, garantindo uma posição sólida aos bancos comerciais.

A Lei 486 de 1925 institui o Banco Central chileno o qual possui um conselho monetário que é encarregado das diretrizes da política monetária, de crédito, de comércio exterior e do mercado de capitais. É composto por cinco membros e cada integrante é designado por um período de dez anos, exceto o presidente que permanece no cargo por cinco anos. O Chile foi pioneiro na América Latina em adotar o regime de metas de inflação que se deu no último trimestre de 1990, e opera a política monetária com plena autonomia para evitar as pressões associadas a ciclos políticos como tratam BBC (2016) e Corbo e Hernández (2005). O arranjo cambial, adotado a partir de 1999, é o de taxa de câmbio flutuante, com intervenções esporádicas do Banco Central com metas de inflação de 3\% e uma tolerância de 1\% para mais ou para menos. Além disso, a condução da política monetária é de maneira transparente, com relatórios publicados periodicamente.

O Banco Central do México foi criado também em 1925 e ao longo dos anos 1990 experimentou diversos tipos de políticas monetárias e cambiais, as quais se pode dividir em três grandes grupos, (i) meta cambial de bandas que resistiu até a crise financeira de 1994, (ii) regime metas para o agregado monetário e a livre flutuação do câmbio, e (iii) regime de metas de inflação a partir de 1999 como mostram Galindo e Ros (2006). De forma similar o Banco Central Chileno, as metas de inflação para economia mexicana também são de 3\% e uma tolerância de 1\% para mais ou para menos O Banco Central mexicano possui autonomia operacional é composto por cinco membros, designados pelo Presidente da República e com aprovação do Senado. 
O Banco Central do Brasil foi criado em 1964 pela Lei n 4595/64 e adotou os sistemas de metas de inflação, em 1999, fixada em 4,5\% com uma tolerância de 2 pontos percentuais. A política monetária passou a ser caracterizada pelo superávit primário, câmbio flutuante e, portanto, por metas de inflação. Além disso foi criado o Comitê de Política Monetária (Copom) com a função de determinar as diretrizes para economia brasileira e a taxa básica de juros como trata de BCB (2016). A Estrutura organizacional é formada por um presidente e oito diretores. Sendo que o presidente é indicado pelo Presidente da República e aprovado pelo Senado.

Por fim, salienta-se que, em alguns casos, a criação dos Bancos Centrais está associada por movimentos revolucionários militares originados por crises econômicas e financeiras causadas, sobretudo pela inconversibilidade da moeda, emitida sem lastro. Esse é o caso típico Revolução militar Juliana de 1925 no Equador que teve o mérito de dar o início do processo da fundação de um banco nacional emissor. No Brasil, a criação do Banco Central do Brasil está vinculada ao golpe em governo militar em que de Castelo Branco que venceu, sob a lei militar, todas as históricas resistências e transformou Sumoc de 1945 para o Banco Central.

\section{Aspectos metodológicos e definição de variáveis}

Para avaliar o desempenho dos Bancos Centrais dos países selecionados da América Latina emprega-se os modelos VAR/VEC ou Vetor Auto-regressivo e/ou o Mecanismo de Correção de Erros. O VAR foi introduzido por Sims (1980) que evidenciou a existência de uma simultaneidade entre um conjunto de variáveis, ou seja, a priori nenhuma delas poderia ser tratada como endógena ou exógena. Enquanto o VEC foi utilizado primeiramente por Hendry, Pagan e Sargan (1984) e popularizado por Engel e Granger, funcionado como um mecanismo que corrige os desequilíbrios relacionados a existência de uma relação de longo prazo, ou seja, das séries serem cointegradas. Outro instrumental utilizado foi a função de impulso-resposta que é importante para a análise de modelos VAR/VEC. Essa função permite simular a reação das variáveis endógenas ao modelo frente a choques exógenos.

Dentre alguns dos principais estudos que se utilizam dessa metodologia destacam-se os que incluíram variáveis como taxa de juros e o câmbio, além de regimes de política monetária como de Sims e Zha, (2002) (2004). Guillén e Garcia (2014) inovam construindo um índice utilizando Cadeias de Markov considerando a dispersão das expectativas para medir a credibilidade do Banco Central. Outros, como Souza e Alves (2010) e Couto e Fraga (2013) utilizam o Mecanismo de Correção de Erros (VEC) para suas estimativas. Esses principais estudos estão sintetizados no Apêndice A.

Outros estudos estimaram para os Estados Unidos por Fuhrer e Moore (1995) e Romer e Romer (2004) a implementação de ações pelo banco central e como elas afetam a economia. Para ambos, o banco central dos Estados Unidos foi eficiente na manutenção do emprego na economia e na estabilização da inflação. Fuhrer e Moore (1995) encontraram evidências de que a política monetária atingiu seus objetivos nos Estados Unidos e desempenhou um papel relevante na interação entre oferta e demanda agregada. Os impactos de transmissão da política monetária para as variáveis macroeconômicas são confirmados por Romer e Romer 
(2004). Os autores utilizam uma abordagem conhecida como narrativa, que reconhece quando o banco central atua. Os resultados estão de acordo com o esperado e confirmam as conclusões de Fuhrer e Moore (1995), de que se deve considerar, em alguns casos, certo tempo de resposta até que as variáveis absorvam os efeitos de transmissão da política monetária.

No que tange à definição das variáveis, são aquelas comumente usadas na literatura que permite identificar o desempenho e a consistência da política monetária. As variáveis empregadas, ao longo do período de 2000 a 2014, possuem periocidade mensal com transformação logarítmica e dessazonalizadas baseado no método Census X12 Multiplicativo -para os dados do Chile foi utilizado o Aditivo devido a existência de valores zeros e negativos- as quais são: a) Índice da variação mensal dos índices de preços de cada país, IP; b) taxa de juros efetiva de cada país e anualizada, TJ e c) o índice de taxa de câmbio real efetivo, TC. As duas últimas representam o comportamento do Banco Central, levando em consideração os entraves e expansões econômicas e com isso objetiva-se averiguar a influências das decisões deste, sobre os preços da economia. As séries estatísticas foram coletadas junto aos bancos centrais de cada país que servem como guia para a elaboração da política monetária e ao Fundo Monetário Internacional (FMI).

O VEC possibilita a adoção de um sistema em que todas as variáveis possam ter influência recíproca, além de fazer o uso de variáveis defasadas. A estimação é efetuada com as variáveis em diferença (curto prazo), contudo, preservando as informações de longo prazo. Uma forma genérica da equação definida para as estimativas pode ser representada por:

$$
\Delta I P_{t}=\pi_{0}+\alpha I P_{t-1}+\pi_{i} \Delta I P_{t-i}+\sum \gamma_{i} \Delta T C_{t-i}+\sum \delta_{i} \Delta T J_{t-i}+u_{t}
$$

Onde: $\Delta Y_{t}$ é o vetor $(\mathrm{n} \times 1)$ de variáveis endógenas; $\pi_{0}$ é o vetor $(\mathrm{n} \times 1)$ dos termos de intercepto; $a$ é o vetor $n \times 1$ de cointegração ou os coeficientes de ajuste de longo prazo do modela; $\pi_{i}$ é a matriz ( $\mathrm{n} \times \mathrm{n}$ ) associada aos parâmetros das variáveis endógenas do modelo; $\beta_{i} \gamma_{i} e \delta_{i}$ são as matrizes ( $\mathrm{n} \times \mathrm{n}$ ) associadas aos parâmetros do vetor $(\mathrm{n} \times 1)$ das variáveis exógenas (taxa de juros efetiva de cada país e anualizada e, o índice de taxa de câmbio real efetivo, respectivamente); $u_{t}$ é o vetor ( $\mathrm{n} \times 1$ ) de resíduos ou erros estocásticos.

\section{Análise e descrição de resultados}

A projeção de crescimento do FMI para os países da América Latina se estabelecia em 2,5\% no ano de 2014. Mais 2015 representou o quinto ano consecutivo de desaceleração da atividade econômica na região. Enquanto alguns países do sul, a exemplo de Chile, representavam uma maior expectativa de crescimento para 2015, em comparação com 2014, outros como Brasil viram sua economia desacelerar mais profundamente. Enquanto ao norte, o México representa uma possibilidade de crescimento moderado.

Uma das principais alterações de Política Monetária dos países latino americanos entre as décadas de 1990 e 2000, foi a adoção, dos regimes de metas. Mishkin (2000) enfatiza que o regime de metas inflacionárias é uma estratégia de política monetária. O principal instrumento 
de política monetária passa a ser a taxa de juros, de responsabilidade dos bancos centrais, o que torna sua atuação ainda mais relevante. Cronologicamente Brasil, Chile e México visando solucionar problemas de inflação e estabilidade de preços foram os primeiros a adotar o regime. O quadro 1 apresenta uma síntese dos indicadores dos regimes de metas dos países da América Latina analisados no estudo.

A redução inflacionária dada a implementação do sistema de metas de inflação, é notável em todos os países da América Latina. No entanto, a implementação do sistema de metas inflacionárias não foi acompanhado de expansão no crescimento de todos os países, como é o caso do Chile e do México. O primeiro teve a média de crescimento reduzida de uma média de 6,37\% nos anos 1990 para 4,17\% entre 2000-2013, no caso do segundo, a média de crescimento passou de 3,38\% para 2,53\% (FMI, 2016).

Quadro 1. Sínteses dos indicadores dos regimes de metas dos países da América Latina avaliados no estudo

\begin{tabular}{|c|c|c|c|}
\hline Indicadores & Brasil & Chile & México \\
\hline Adoção & 1999 & $1990 /{ }^{*} 1999$ & 1999 \\
\hline $\begin{array}{c}\text { Institutional/ } \\
\text { CMNação da meta }\end{array}$ & BC & BC & $\begin{array}{c}\text { Governo e BC } \\
\text { Indepen. }\end{array}$ \\
\hline Objetivo & $\begin{array}{c}\text { Estabilidade dos preços e } \\
\text { do Sistema financeiro }\end{array}$ & Inflação baixa e estável & $\begin{array}{c}\text { Estabilidade da } \\
\text { moeda e do Sistema } \\
\text { financeiro }\end{array}$ \\
\hline Índice de referência & IPCA & IPCA & IPC \\
\hline Horizonte temporal & Anual & Bianual & $\begin{array}{c}\text { Curto prazo - } 12 \\
\text { meses }\end{array}$ \\
\hline Inst. Política Monetária & Taxa de juros Over/ Selic & Taxa de juros Overnight & $\begin{array}{c}\text { Regulação da } \\
\text { liquidez }\end{array}$ \\
\hline Meta atual (\%) & $4,5+/-2$ & $3,0+/-1$ & $3,0+/-1$ \\
\hline Taxa de Inflação na \\
adoção (\%)
\end{tabular}

Fonte: Bancos centrais dos países e Hammond (2012).

* Informal e formal respectivamente. ** Exclusão dos preços dos alimentos e de alguns preços administrados. ${ }^{* *} \%$ ao ano em dez/2014.

Nota: CMN significa Conselho Monetário Nacional e BC Banco Central.

A tabela 1 apresenta um resumo das informações estatísticas das variáveis para cada um dos modelos estimados. As duas primeiras são medidas de tendência central, como a média e a mediana. Depois são reportados o valor máximo e o valor mínimo de cada variável do conjunto de dados. Destaca-se, também, o resultado para o teste e normalidade de Jarque-Bera, que verifica se um conjunto de dados possui uma distribuição normal ou não. Com base em um nível de significância de $10 \%$ as séries de índice de preço e taxa de juros brasileiras, além do índice de taxa de câmbio real efetivo e taxa de juros mexicanos caracterizaram-se a partir do teste e normalidade de Jarque-Bera como apresentando uma distribuição normal. 
Tabela 1. Resumo Estatístico das Variáveis Utilizadas em Cada Modelo*

\begin{tabular}{|c|c|c|c|c|c|c|c|c|c|}
\hline & \multicolumn{3}{|c|}{ Brasil (1) } & \multicolumn{3}{|c|}{ Chile (2) } & \multicolumn{3}{|c|}{ México (3) } \\
\hline & LIP & LTC & LTJ & LIP & LTC & LTJ & LIP & LTC & LTJ \\
\hline Média & 0,507 & 0,779 & 2,593 & 0,241 & 6,321 & 1,318 & 0,367 & 2,433 & 1,926 \\
\hline Mediana & 0,519 & 0,768 & 2,567 & 0,225 & 6,285 & 1,565 & 0,360 & 2,411 & 1,996 \\
\hline Máximo & 0,940 & 1,316 & 3,263 & 0,488 & 6,620 & 2,607 & 0,674 & 2,678 & 2,966 \\
\hline Mínimo & 0,009 & 0,456 & 1,962 & 0,005 & 6,096 & $-0,953$ & 0,010 & 2,204 & 1,191 \\
\hline Desvio Padrão & 0,263 & 0,203 & 0,329 & 0,142 & 0,125 & 0,729 & 0,186 & 0,125 & 0,420 \\
\hline Jaque-Bera & 8,770 & 10,027 & 5,767 & 14,876 & 12,161 & 110,090 & 10,163 & 9,000 & 7,649 \\
\hline $\mathrm{p}$-valor & 0,012 & 0,007 & 0,056 & 0,001 & 0,002 & 0,000 & 0,006 & 0,011 & 0,022 \\
\hline Observações & 180 & 180 & 180 & 180 & 180 & 180 & 180 & 180 & 180 \\
\hline
\end{tabular}

* Variáveis na forma logarítmica e dessazonalizadas

Fonte: elaboração própria.

Com relação ao índice de preços a maior média refere-se aos dados para o Brasil, o mesmo se verifica com observados os dados da variável sem tratamento apresentados pela figura 1.0 Índice apresentou uma trajetória crescente para os três países, sendo que o Brasil apresentou as maiores variações seguidas pelo México e Chile, respectivamente. A média de taxa de juros Chilenas também foram as menores, o que condiz com relação a situação de seu índice de preços. Quanto as taxas de crescimento do produto em 2015, destacam-se as piores a exemplo do Brasil $(-3,8)$ enquanto Chile e México tiveram um crescimento positivo, sendo, nesta ordem $2,1 \%$ e $2,5 \%$ de acordo com dados do FMI (2016).

Figura 1. Índice de Preços para Brasil, Chile e México com variação mensal de Jan/2000 a Dez/2014

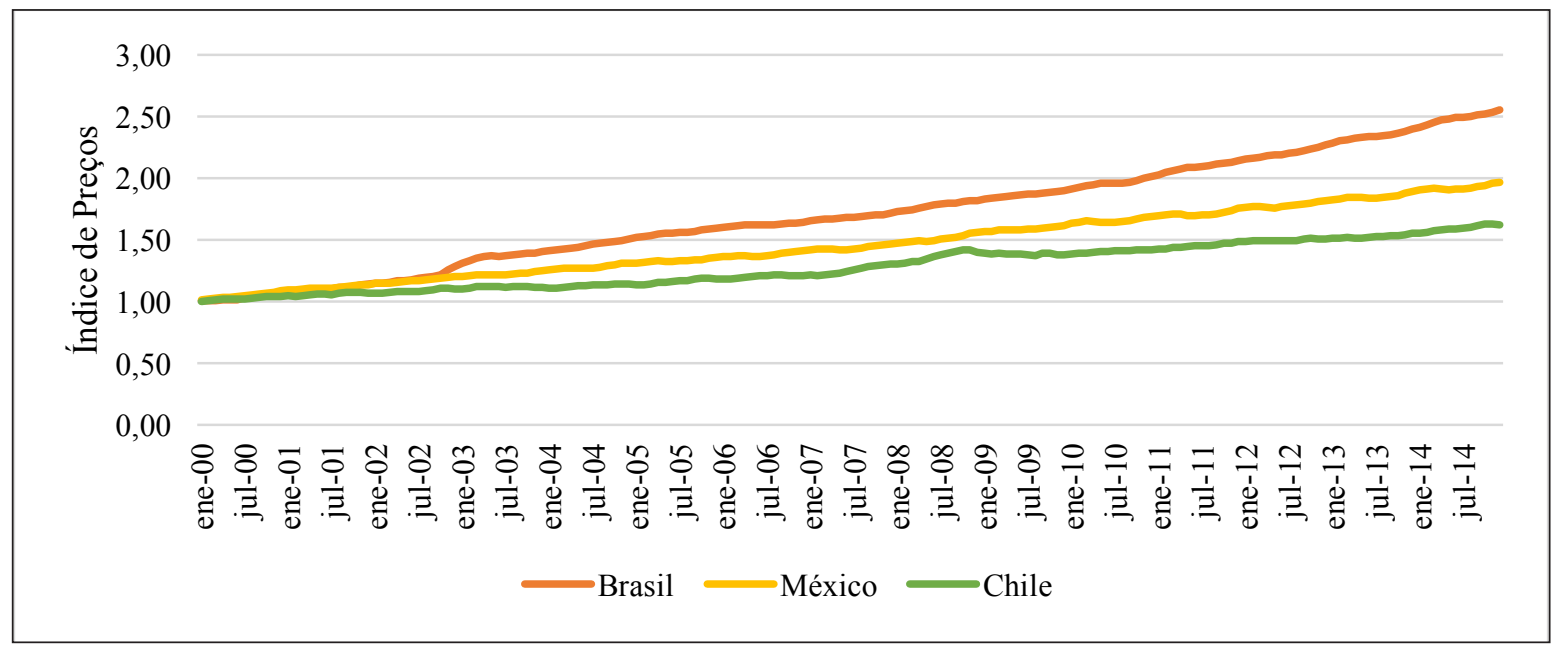

Fonte: FMI (2016). 
O procedimento inicial realizado para obtenção dos coeficientes estimados dos modelos foi a investigação de estacionariedade das séries por meio de testes de raiz unitária. Para isso empregou-se o teste ADF (Augmented Dickey-Fuller) cuja hipótese nula é de existência de raiz unitária. Assim, foram encontrados indícios de não estacionariedade em todas as variáveis compreendidas relacionadas aos três modelos. A ordem de integração é I(1), e quando transformadas em diferença, as variáveis tornam-se estacionárias, ou seja, I(0). A tabela 2 apresenta os resultados do teste.

Tabela 2. Teste de Raiz Unitária*

\begin{tabular}{|c|c|c|c|c|c|c|c|c|}
\hline \multicolumn{9}{|c|}{ Brasil } \\
\hline & Série & $\tau_{\tau}$ & $\mathrm{p}$ valor & $\tau_{\mu}$ & $p$ valor & $\tau$ & $p$ valor & Integração \\
\hline \multirow{3}{*}{ ADF } & lip_sa & -2.287 & 0.438 & -1.845 & 0.3570 & 2.343 & 0.995 & $\mathrm{I}(1)$ \\
\hline & Itc_sa & -2.133 & 0.523 & -1.885 & 0.338 & 0.042 & 0.694 & $\mathrm{I}(1)$ \\
\hline & Itj_sa & -3.613 & 0.031 & -1.729 & 0.414 & -0.544 & 0.4799 & $\mathrm{I}(1)$ \\
\hline \multirow{3}{*}{$\Delta \mathrm{ADF}$} & lip_sa & -5.497 & 0.000 & -5.266 & 0.000 & -2.427 & 0.015 & $\mathrm{I}(0)$ \\
\hline & Itc_sa & -8.738 & 0.000 & -8.762 & 0.000 & -8.765 & 0.000 & $\mathrm{I}(0)$ \\
\hline & Itj_sa & -4.844 & 0.000 & -4.845 & 0.000 & -4.849 & 0.000 & $I(0)$ \\
\hline \multicolumn{9}{|c|}{ Chile } \\
\hline \multirow{3}{*}{ ADF } & lip_sa & -1.712 & 0.7421 & -0.034 & 0.953 & 3.082 & 0.999 & $\mathrm{I}(1)$ \\
\hline & Itc_sa & -2.440 & 0.3576 & -1.925 & 0.319 & 0.348 & 0.784 & $\mathrm{I}(1)$ \\
\hline & Itj_sa & -3.424 & 0.051 & -3.461 & 0.010 & -1.915 & 0.053 & $\mathrm{I}(1)$ \\
\hline \multirow{3}{*}{$\Delta \mathrm{ADF}$} & lip_sa & -5.895 & 0.000 & -5.902 & 0.000 & -2.624 & 0.008 & $\mathrm{I}(0)$ \\
\hline & Itc_sa & -9.377 & 0.000 & -9.403 & 0.000 & -9.419 & 0.000 & $\mathrm{I}(0)$ \\
\hline & Itj_sa & -4.312 & 0.003 & -4.300 & 0.000 & -4.296 & 0.000 & $\mathrm{I}(0)$ \\
\hline \multicolumn{9}{|c|}{ México } \\
\hline \multirow{3}{*}{ ADF } & lip_sa & -4.220 & 0.005 & -2.360 & 0.154 & 1.817 & 0.983 & $\mathrm{I}(1)$ \\
\hline & Itc_sa & -3.502 & 0.042 & -1.382 & 0.590 & 1.023 & 0.919 & $\mathrm{I}(1)$ \\
\hline & Itj_sa & -2.157 & 0.510 & -1.470 & 0.546 & -2.299 & 0.021 & $\mathrm{I}(1)$ \\
\hline \multirow{3}{*}{$\Delta A D F$} & lip_sa & -16.652 & 0.000 & -16.338 & 0.000 & -1.333 & 0.168 & $\mathrm{I}(0)$ \\
\hline & Itc_sa & -9.785 & 0.000 & -9.816 & 0.000 & -9.752 & 0.000 & $\mathrm{I}(0)$ \\
\hline & Itj_sa & -12.219 & 0.000 & -12.253 & 0.000 & -12.068 & 0.000 & $\mathrm{I}(0)$ \\
\hline
\end{tabular}

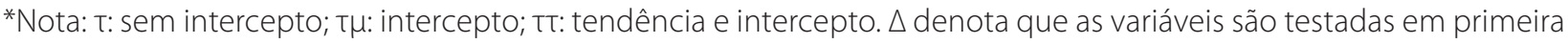
diferença. Teste considerando o Critério de Schwarz com número máximo de 13 lags.

Fonte: elaboração própria.

Para verificar a credibilidade da atuação dos Bancos Centrais dadas as mudanças no comportamento da política monetária estimou-se três modelos VAR/VEC irrestrito, como o descrito pela equação (01), buscando averiguar a influência dos principais instrumentos monetários, sendo estes a taxa de câmbio e de juros no nível de preços da economia. Com a finalidade de avaliar a presença de uma relação de longo prazo entre as variáveis dos modelos, realizou-se o teste de cointegração de Johansen, considerando a presença de intercepto no vetor de cointegração. A hipótese nula de não existência de vetores de cointegração é rejeitada ao nível 
de confiança de $95 \%$ conforme mostra a tabela 3 . As variáveis demonstram, portanto, uma relação de longo prazo, desta forma a utilização do Mecanismo de Correção de Erros é a mais adequada, sem que ocorra perda de informações de longo prazo nos modelos.

Tabela 3. Teste de cointegração de Johansen

\begin{tabular}{|c|c|c|c|c|c|}
\hline No de Vetores de Cointegração & Autovalor & Estatística Traço & Valor Crítico & $\begin{array}{c}\text { Estatística Max. } \\
\text { Autovalor }\end{array}$ & Valor Crítico \\
\hline \multicolumn{6}{|c|}{ Brasil (1) } \\
\hline $\mathrm{r}=0$ & 0,225368 & 90,320 & 29,797 & 44,944 & 21,131 \\
\hline $\mathrm{r} \leq 1$ & 0,155294 & 45,375 & 15,494 & 29,702 & 14,266 \\
\hline $\mathrm{r} \leq 2$ & 0,085202 & 15,673 & 3,841 & 15,673 & 3,841 \\
\hline \multicolumn{7}{|c|}{ Chile (2) } \\
\hline $\mathrm{r}=0$ & 0,231101 & 113,950 & 29,797 & 46,252 & 21,131 \\
\hline $\mathrm{r} \leq 1$ & 0,201469 & 67,698 & 15,494 & 39,596 & 14,264 \\
\hline $\mathrm{r} \leq 2$ & 0,147573 & 28,101 & 3,841 & 28,101 & 3,841 \\
\hline \multicolumn{7}{|c|}{ México (2) } \\
\hline $\mathrm{r}=0$ & 0,30359 & 139,402 & 29,797 & 63,679 & 21,131 \\
\hline $\mathrm{r} \leq 1$ & 0,225922 & 75,723 & 15,494 & 45,070 & 14,264 \\
\hline $\mathrm{r} \leq 2$ & 0,159839 & 30,652 & 3,841 & 30,652 & 3,841 \\
\hline
\end{tabular}

Fonte: elaboração própria, software EViews 9.0.

Para avaliar a autocorrelação dos resíduos aplicou-se o teste de autocorrelação LM, sob hipótese nula de ausência de autocorrelação, para um máximo de 3 lags cujos resultados estão descritos na tabela 4. Para os Modelos 2 e 3 para um nível de confiança de $99 \%$ os resíduos não são autocorrelacionados, no caso do modelo 1 a ausência de correlação é observada a partir do 2 lag. A Heterocedasticidade dos resíduos foi testada por meio do teste White, identificando, para os três modelos resíduos Homocedasticos.

A defasagem ótima, $p$, escolhida para cada modelo é baseada em dois critérios comumente utilizados Akaike (AIC) e Schwarz (SC). Seguindo o pressuposto de minimização destes, foram definidas duas defasagens para cada modelo, os resultados estão descritos na tabela 5.

A partir das estimativas dos coeficientes, através do Mecanismo de Correção de Erros, é possível observar que no caso do Brasil o índice de taxa de câmbio (TC) teve inferência significativa aos níveis de significância considerados (10\% e 5\%) na determinação da variável mensal do índice de preços da economia do país. Ou seja, pode-se dizer que uma variação de $1 \%$ no índice de taxa de câmbio brasileiro do período anterior provoca uma variação sentido oposto de 0,027\% no índice de preços mensal do período atual. Verificando que a atuação do BC com determinação desta variável tem tido inferência relevante na economia do país no período avaliado. $A$ variável do índice de preços mensal do período anterior inferência significativa (ao nível de 5\% de significância) na determinação do índice de taxa de câmbio do período atual, onde uma alteração de $1 \%$ na primeira provocaria uma variação no sentido oposto de $2,67 \%$ na segunda. As demais variáveis na sua maioria se estabeleceram como insignificantes aos níveis considerados. 
Tabela 4. Teste de autocorrelação LM para um máximo de 3 Lags

\begin{tabular}{|c|c|c|c|c|c|c|}
\hline & \multicolumn{2}{|c|}{ Brasil (1) } & \multicolumn{2}{c|}{ Chile (2) } & \multicolumn{2}{c|}{ México (3) } \\
\hline Lags & LM-Stat & Prob & LM-Stat & Prob & LM-Stat & Prob \\
\hline 1 & 9,274 & 0,412 & 28,288 & 0,000 & 29,005 & 0,000 \\
\hline 2 & 21,513 & 0,010 & 33,632 & 0,000 & 40,733 & 0,000 \\
3 & 24,078 & 0,004 & 21.872 & 0,009 & 35,420 & 0,000 \\
\hline
\end{tabular}

Fonte: elaboração própria.

Tabela 5. Escolha da Defasagem Ótima para cada modelo

\begin{tabular}{|c|c|c|c|}
\hline Modelo & $\mathbf{N}$ o Lags & AIC & SC \\
\hline \multirow{3}{*}{ Brasil (1) } & 1 Lags & $-16,757$ & $-16,434$ \\
\cline { 2 - 4 } & 2 Lags & $-16,848$ & $-16,362$ \\
\cline { 2 - 4 } & 3 Lags & $-16,806$ & $-16,155$ \\
\hline \multirow{3}{*}{ Chile (2) } & 1 Lags & $-12,692$ & $-12,369$ \\
\cline { 2 - 4 } & 2 Lags & $-12,874$ & $-12,388$ \\
\cline { 2 - 4 } & 3 Lags & $-13,006$ & $-12,355$ \\
\hline \multirow{3}{*}{ México (3) } & 1 Lags & $-15,532$ & $-15,209$ \\
\cline { 2 - 4 } & 2 Lags & $-15,768$ & $-15,281$ \\
\cline { 2 - 4 } & 3 Lags & $-15,879$ & $-15,228$ \\
\hline
\end{tabular}

Fonte: elaboração própria. Considerou-se principalmente o critério de Schwarz.

Com relação ao Chile o índice de taxa de câmbio (TC) aos níveis de significância considerados (10\% e 5\%) provoca modificações significativas na determinação da variável mensal do índice de preços da economia do país do período atual, sendo que uma variação de $1 \%$ no índice de taxa de câmbio chileno do período anterior provoca uma variação no mesmo sentido de $0,08 \%$ no índice de preços do período atual. A taxa de juros não teve influência significativa sobre as demais variáveis. Para o México é possível observar que as variáveis relacionadas a atuação do $B C$ na economia, como taxa de juros e taxa de câmbio não tiveram atuação significativa quando observadas alterações provocadas no índice de preços. O índice de preços do período anterior, no entanto, quando variado em $1 \%$ provoca uma alteração no índice de taxa de câmbio de cerca de $-2 \%$. Enquanto o índice de taxa de câmbio mexicana do período anterior tem influência significativa na determinação da taxa de juros do período atual, tendendo a elevar a segunda.

A tabela 6 apresenta uma síntese dos coeficientes estimados através do Mecanismo de Correção de Erros para os três modelos. O modelo 1 apresenta os resultados para o Brasil, enquanto o 2 e 3 para Chile e México, respectivamente. São reportados os coeficientes, logo abaixo desses seus desvios padrões e entre chaves a estatística $t$ relacionada. Por fim são apresentados os coeficientes de ajustamento dos modelos, sendo que os resultados obtidos foram considerados satisfatórios.

Utilizou-se a função impulso resposta para verificar qual a resposta da variável analisadas a choques externos. De acordo com Hamilton (1994), a função de impulso resposta é compostas 
por uma matriz de multiplicadores de impacto de um choque sobre as variáveis endógenas. As linhas e colunas da matriz capturam as consequências de uma inovação, no valor da i-ésima variável no tempo. $O$ formato da função de impulso resposta considerado é a generalizada, portanto, a ordenação das variáveis não interfere nos resultados.

Tabela 6. Síntese dos Coeficientes estimados para os três modelos com duas defasagens

\begin{tabular}{|c|c|c|c|c|c|c|c|c|c|}
\hline & \multicolumn{3}{|c|}{ Modelo 1 Brasil } & \multicolumn{3}{|c|}{ Modelo 2 Chile } & \multicolumn{3}{|c|}{ Modelo 3 México } \\
\hline $\begin{array}{c}\text { Vetor de } \\
\text { Correção de } \\
\text { Erros } \\
\end{array}$ & $\begin{array}{l}\Delta \text { Índice de } \\
\text { Preços }\end{array}$ & $\begin{array}{c}\Delta \text { Índice de } \\
\text { Taxa de } \\
\text { Câmbio }\end{array}$ & $\Delta$ Taxa de Juros & $\begin{array}{l}\Delta \text { Índice de } \\
\text { Preços }\end{array}$ & $\begin{array}{c}\Delta \text { Índice de } \\
\text { Taxa de } \\
\text { Câmbio }\end{array}$ & $\Delta$ Taxa de Juros & $\begin{array}{l}\Delta \text { Índice de } \\
\text { Preços }\end{array}$ & $\begin{array}{c}\Delta \text { Índice de } \\
\text { Taxa de } \\
\text { Câmbio }\end{array}$ & $\Delta$ Taxa de Juros \\
\hline \multirow{3}{*}{$\begin{array}{c}\Delta \text { Índice de } \\
\text { Preços(-1) }\end{array}$} & $-0,494869$ & -2.674 .324 & $-0,02647$ & $-0,681641$ & 0,181095 & 0,800985 & $-0,035756$ & -2.008 .465 & -1.873 .177 \\
\hline & $-0,07184$ & $-0,58334$ & $-0,33271$ & $-0,06892$ & $-0,35471$ & -262.237 & $-0,11188$ & $-0,83297$ & -216.797 \\
\hline & {$[-6.88826]$} & {$[-4.58448]$} & {$[-0.07956]$} & {$[-9.89049]$} & {$[0.51054]$} & {$[0.30544]$} & {$[-0.31959]$} & {$[-2.41119]$} & {$[-0.86402]$} \\
\hline \multirow{3}{*}{$\begin{array}{c}\Delta \text { Índice de } \\
\text { Preços(-2) }\end{array}$} & $-0,30084$ & -1.358 .231 & 0,885264 & $-0,497977$ & 0,432065 & -2.680 .616 & 0,026131 & -1.699 .659 & -3.987 .279 \\
\hline & $-0,06977$ & $-0,56651$ & $-0,32311$ & $-0,06745$ & $-0,34714$ & -256.639 & $-0,07323$ & $-0,5452$ & -141.899 \\
\hline & {$[-4.31195]$} & {$[-2.39756]$} & [ 2.73984] & {$[-7.38317]$} & [ 1.24465$]$ & {$[-1.04451]$} & [ 0.35684$]$ & {$[-3.11747]$} & {$[-2.80994]$} \\
\hline \multirow{3}{*}{$\begin{array}{c}\Delta \text { Índice } \\
\text { de Taxa de } \\
\text { Câmbio(-1) }\end{array}$} & $-0,027247$ & $-0,091685$ & $-0,015589$ & 0,081017 & 0,018898 & 0,353678 & $-0,015034$ & $-0,282651$ & 0,381359 \\
\hline & $-0,01139$ & $-0,09245$ & $-0,05273$ & $-0,01809$ & $-0,09313$ & $-0,6885$ & $-0,01119$ & $-0,08334$ & $-0,21692$ \\
\hline & {$[-2.39304]$} & {$[-0.99171]$} & {$[-0.29565]$} & {$[4.47743]$} & {$[0.20293]$} & {$[0.51369]$} & {$[-1.34297]$} & {$[-3.39141]$} & {$[1.75810]$} \\
\hline \multirow{3}{*}{$\begin{array}{c}\Delta \text { Índice } \\
\text { de Taxa de } \\
\text { Câmbio(-2) }\end{array}$} & $-0,014885$ & $-0,055572$ & $-0,050487$ & 0,050261 & 0,046878 & 1.233 .245 & $-0,010386$ & $-0,211371$ & 0,594719 \\
\hline & $-0,00974$ & $-0,07912$ & $-0,04512$ & $-0,01573$ & $-0,08098$ & $-0,5987$ & $-0,01059$ & $-0,07885$ & $-0,20523$ \\
\hline & {$[-1.52768]$} & {$[-0.70240]$} & {$[-1.11883]$} & [ 3.19436] & [ 0.57888] & [ 2.05988] & {$[-0.98063]$} & {$[-2.68058]$} & [ 2.89785] \\
\hline \multirow{3}{*}{$\begin{array}{l}\Delta \text { Taxa de } \\
\text { Juros(-1) }\end{array}$} & $-0,001111$ & $-0,03422$ & $-0,118597$ & $-0,000224$ & $-0,0107$ & $-0,662134$ & $-0,00567$ & $-0,039623$ & $-0,644805$ \\
\hline & $-0,01626$ & $-0,13202$ & $-0,0753$ & $-0,00193$ & $-0,00993$ & $-0,07341$ & $-0,00377$ & $-0,02804$ & $-0,07299$ \\
\hline & {$[-0.06835]$} & {$[-0.25921]$} & {$[-1.57509]$} & {$[-0.11621]$} & {$[-1.07756]$} & {$[-9.01957]$} & {$[-1.50531]$} & {$[-1.41290]$} & {$[-8.83418]$} \\
\hline \multirow{3}{*}{$\begin{array}{l}\Delta \text { Taxa de } \\
\text { Juros(-2) }\end{array}$} & 0,016701 & 0,283714 & $-0,003482$ & 0,001302 & $-0,007807$ & $-0,25587$ & 0,000709 & 0,014523 & $-0,369442$ \\
\hline & $-0,01615$ & $-0,13116$ & $-0,07481$ & $-0,0019$ & $-0,00976$ & $-0,07216$ & $-0,00368$ & $-0,02737$ & $-0,07125$ \\
\hline & [ 1.03394$]$ & [ 2.16317] & {$[-0.04654]$} & [ 0.68653] & {$[-0.79985]$} & {$[-3.54600]$} & [ 0.19291] & [ 0.53053] & {$[-5.18528]$} \\
\hline \multirow{3}{*}{ Constante } & $5,70 \mathrm{E}-05$ & 0,000173 & 0,000262 & $-2,09 \mathrm{E}-05$ & 1,41E-05 & $-0,002022$ & $2,33 E-05$ & 0,000172 & $2,45 E-05$ \\
\hline & $-0,00032$ & $-0,0026$ & $-0,00148$ & $-0,00036$ & $-0,00186$ & $-0,01376$ & $-0,00025$ & $-0,00184$ & $-0,0048$ \\
\hline & [ 0.17821$]$ & {$[0.06676]$} & [ 0.17702$]$ & {$[-0.05788]$} & {$[0.00758]$} & {$[-0.14696]$} & [ 0.09419] & [ 0.09352] & {$[0.00510]$} \\
\hline R-squared & 0,412454 & 0,298042 & 0,092156 & 0,480299 & 0,334933 & 0,383503 & 0,61507 & 0,24432 & 0,43033 \\
\hline \begin{tabular}{|c|}
$\begin{array}{c}\text { Adj. R-squa- } \\
\text { red }\end{array}$ \\
\end{tabular} & 0,387973 & 0,268794 & 0,054329 & 0,458645 & 0,307222 & 0,357815 & 0,599031 & 0,212833 & 0,406594 \\
\hline
\end{tabular}

Fonte: elaboração própria.

A figura 2 representa os resultados para o Brasil, para a variável de índices de preços quando ocorre um choque generalizado no índice de taxa de câmbio e taxa de juros para dez períodos. Identifica-se que um os choques tanto na taxa de juros como no índice de taxa de câmbio tem uma resposta relevante nas variável considerada. Ambas após o choque impactaram positivamente no índice de preços, porém o choque no índice de taxa de câmbio foi mais expressivo após um primeiro período negativo. O choque provocado pela taxa de juros se estabiliza a partir do terceiro período. 
Quando ao impacto dos choques no Chile, identifica-se que o choque no índice de taxa de câmbio produz uma queda abrupta no índice de preços, apresentando um efeito negativo após o terceiro período. Enquanto, o choque na taxa de juros produz um efeito mais moderado no índice de preços. Mantendo o mesmo positivo e sem muita variação como uma pequena elevação após o segundo período. Esses impactos podem ser observados na figura 3.

Figura 2. Função Impulso-Resposta para o Brasil

Resposta do Índice de Preço a um choque generalizado no Índice de Taxa de Câmbio e Taxa de Juros

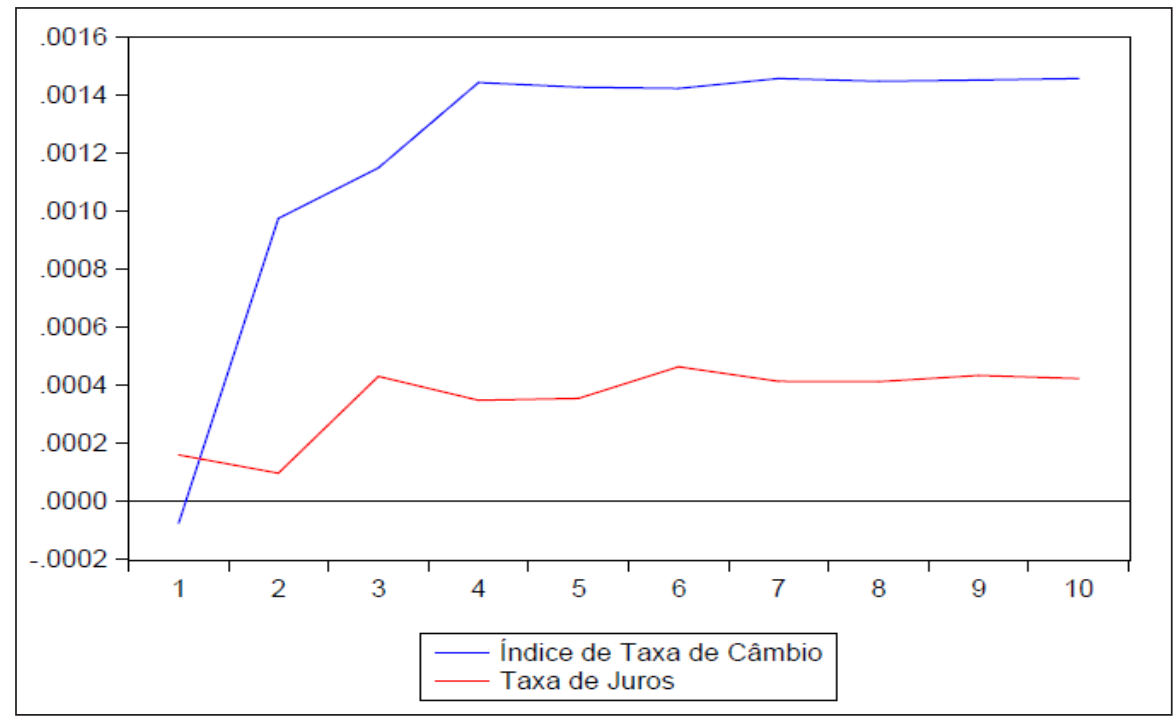

Fonte: elaboração própria.

Figura 3. Função Impulso-Resposta para o Chile

Resposta do Índice de Preço a um choque generalizado no Índice de Taxa de Câmbio e Taxa de Juros

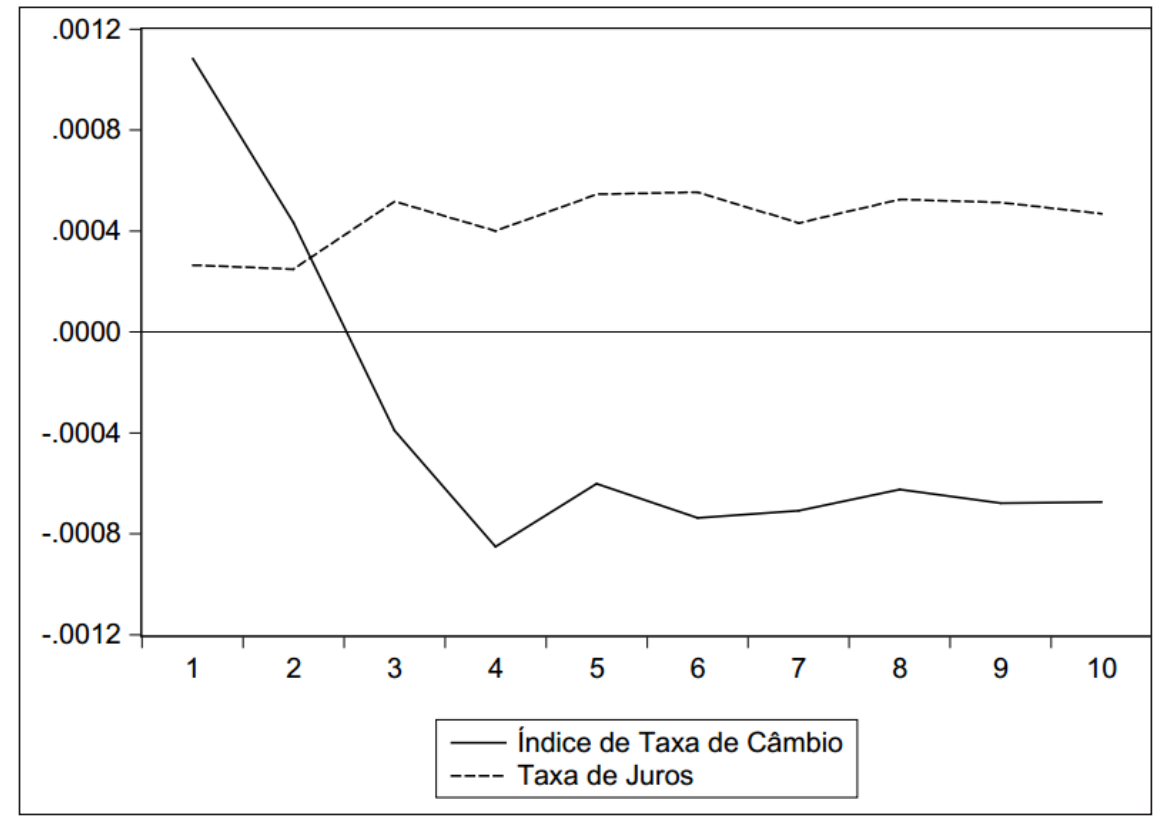

Fonte: elaboração própria.

tiempo\&economía

Vol. 5 N. ${ }^{\circ} 1$ - Enero - Junio de 2018

p. 115 
No México (figura 4) um choque na taxa de juros apresenta um impacto positivo no índice de preços, com uma variação mais significativa entre o segundo e quarto período. Um choque no índice de taxa de câmbio produz uma elevação repentina no índice de preços mexicano, que se mantem elevado no restante do período, porém verifica-se uma redução no terceiro período que revertida no quarto e estabiliza-se a partir do quinto.

Figura 4. Função Impulso-Resposta para o México

Resposta do Índice de Preços a um choque generalizado no Índice de Taxa de Câmbio e Taxa de Juros

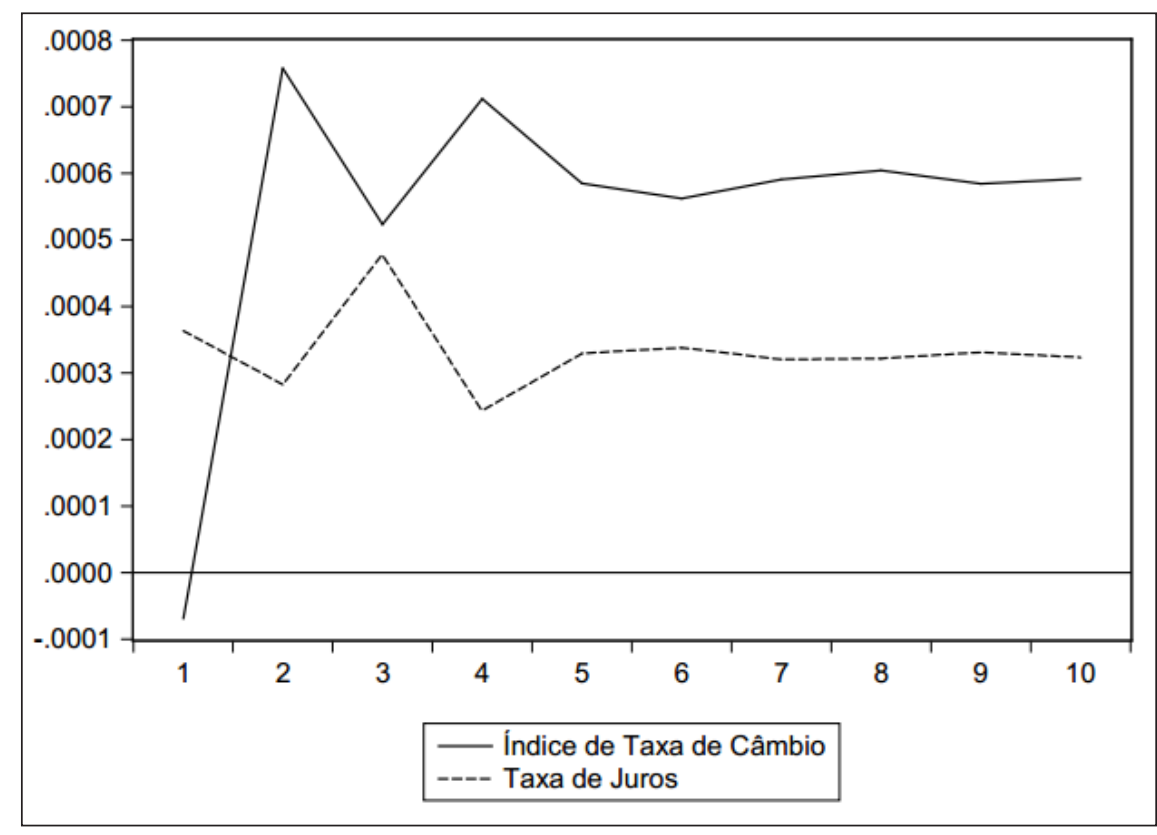

Fonte: elaboração própria.

Os testes de causalidade de Granger, reportados na tabela A1 no apêndice, com duas defasagens, permitem uma melhor interpretação e o sentido das funções impulso resposta. Percebe-se que em poucas variáveis é possível rejeitar a hipótese nula de que uma variável não causa no sentido Granger à outra, ao nível de significância de 5\%. Observa-se que para o modelo 1 relacionado ao Brasil, as variações do índice de taxa de câmbio causam as variações no índice de preços e as variações da taxa de juros causam as variações da variável Índice de taxa de câmbio. Para o modelo 2 do Chile, as variações da taxa de juros causam as variações no índice de preços, enquanto variações no Índice de preços causam variações no índice de taxa de câmbio e taxa de juros. No caso do México, terceiro modelo, as variações da taxa de juros e no índice de taxa de câmbio causam as variações no índice de preços.

\section{Conclusões}

Analisando as estimativas dos coeficientes para os três modelos, é possível observar que no caso do Brasil e Chile, o índice de taxa de câmbio (тс) teve influência significativa na determinação do índice de preços da economia. No modelo para o Brasil uma variação de $1 \%$ no 
índice de taxa de câmbio do período anterior provoca uma variação sentido oposto de 0,027\% no índice de preços mensal do período atual, para o caso do Chile, variações de 1\% no índice de taxa de câmbio chileno do período anterior provocam uma variação no mesmo sentido de 0,08\% no índice de preços do período atual. Para o México, no entanto, tanto o índice de taxa de câmbio quanto a taxa de juros não apresentaram influência significativa sobre o índice de preços. Em um contexto macroeconômico, o México, em conjunto com Brasil e Chile, sofre um período de convergência regulatória pós-crise, apesar das estimativas para o país, com relação a atuação do BC não se apresentarem necessariamente significativas.

A função impulso resposta apresentou modificações relevantes no índice de preços dos três países quando proferido um choque generalizado nas demais variáveis. Para o Brasil, o choque no índice de taxa de câmbio foi mais expressivo após um primeiro período negativo; no Chile, identifica-se que o choque no índice de taxa de câmbio produz uma queda abrupta no índice de preços, apresentando um efeito negativo após o terceiro período e no México um choque na taxa de juros apresenta um impacto positivo no índice de preços e um choque no índice de taxa de câmbio produz uma elevação repentina deste.

Os testes de causalidade de Granger evidenciaram que relacionado ao Brasil, as variações do índice de taxa de câmbio causam as variações no índice de preços, enquanto para o Chile, isso ocorre com a taxa de juros. Em relação ao México, terceiro modelo, as variações da taxa de juros e no índice de taxa de câmbio causa no sentido Granger as variações no índice de preços.

As evoluções financeiras atreladas a globalização e a abertura comercial restringiram a atuação dos agentes reguladores promovendo mudanças com relação a atuação destes para o futuro. Desta forma, a redução de incertezas políticas e econômicas, relacionada a maior inserção dos países no sistema internacional, refletem mudanças nas estratégias dos bancos centrais. O processo de aprimoramento do BC brasileiro é posterior ao chileno, porém a similaridade entre os dois países, tanto na forma de atuação dos agentes, como na desenvoltura econômica caracteriza como relevantes as considerações aqui obtidas.

\section{Referencias}

Arnone, M., Laurens, B., Segalotto, J.-F. y Sommer, M. (2007). Central Bank Autonomy: Lessons from Global Trends. IMF Working Papers, 1-53.

Banco Central do Brasil (BCB). (s.f). Institucional. Recuperado de: http://www.bcb.gov.br/ptbr/\#!/n/laiinstitucional. Acesso em: 18 abr. 2016.

Banco Central do Brasil (BCB). (s.f). Sistema de Metas para a Inflação. Recuperado de: http:// www.bcb.gov.br/pt-br/\#!/n/SISMETAS. Acesso em: 18 abr. 2016.

Banco Central do Chile (BCC). (s.f). Funciones del Banco Central de Chile. Recuperado de: http:// www.bcra.gov.ar/BCRA/bcralns010000.asp. Acesso em: 18 abr. 2016.

Banco do México (BCB)a. (s.f). Acerca del Banco de México. Recuperado de: http://www.banxico.org.mx/acerca-del-banco-de-mexico/acerca-del-banco-mexico.html. Acesso em: 18 abr. 2016. 
Banco do México (BCB)b. (s.f). Historical outline. Recuperado de: http://www.banxico.org.mx/ acerca-del-banco-de-mexico/historical-outline.html. Recuperado de: 18 abr. 2016.

Batista Jr., P. N. (2002). Argentina: uma crise paradigmática. Estud. Av., 16(44), 83-96.

Barro, R. y Gordon, D. (1983). Rules, Discretion, and reputation in a model of monetary policy. Journal of Monetary Economics, 12(1), 101-121.

Blinder, A. S. (2010). How Central Should the Central Bank Be? Journal of Economic Literature, $48,123-133$.

Blinder, A., Ehrmann, M., Haan, J. De, Fratzscher, M. y Jansen, D.J. (2008). Central Bank communication and monetary policy: a survey of theory and evidence. NBER Working Paper No. 13932.

Blinder, A., Goodhart, C., Hildebrans, P., Lipton, D. y Wyplosz, C. (2001). How Do Central Banks Talk? Geneva Reports on the World Economy. 3.

Bucados, E. y Licandro, G. (2003). La demanda de dinero em Uruguay: 1980.1-2002.4. Revista de Economía - Segunda Epoca, X(2), 59-95.

Cobham, D. (2012). The Past, Present, and Future of Central Banking. Oxford Review of Economic Policy, 24(8), 729-749, Recuperado de: http://oxrep.oxfordjournals.org/. Acesso em: 14 mar. 2016.

Corazza, G. (2006). O Banco Central do Brasil: evolução histórica e institucional. Perspectiva Econômica, 2(1), 1-23.

Corbo, V. Y Hernandez, L. (2005). Ochenta Años de Historia del Banco Central de Chile. Documentos de Trabajo. Banco Central de Chile, No. 345.

Couto, S. V. V. y Fraga, G. J. (2013). O pass-though da taxa de câmbio para índices de preços: análise empírica para o Brasil. Revista de Economia Contemporânea, 18(3), 333-356.

Crowe, C. y Meade E. (2007). The Evolution of Central Bank Governance around the World. Journal of Economic Perspectives, 21, 69-90.

Cukierman, A. (1996). A economia do Banco Central. Revista Brasileira de Economia, 50(96), 389-426, Recuperado de: http://bibliotecadigital.fgv.br/ojs/index.php/rbe/article/ view/680/8037. Acesso em: 14 mar. 2016.

Dincer, N. y Eichengreen, B. (2007). Central Bank Transparency: Where, Why, and with What Effects? NBER Working Paper No. 13003.

Faust, J. y Svensson, L. (2001). Transparency and Credibility: Monetary Policy with Unobservable Goals. International Economic Review, 42(2), 369-97.

Fuhrer, J. C. y Moore, G. R. (1995). Monetary policy trade-offs and the correlation between nominal interest rates and real outputs. The American Economic Review, 85, 219-239.

Galindo, L. M. y Ros, J. (2006). Banco de México: política monetaria de metas de inflación. Economía UNAM, 3(9), 82-88.

Geraats, P. M. (2002). Central Bank Transparency. Economic Journal, 112(483), 532-565. 
Goodhart, C. A. (1995). Dinâmicas financeiras privadas e o desafio às políticas dos bancos centrais. Economia e Sociedade, 4, 27-52. Recuperado de: http://www.eco.unicamp.br/docprod/downarq.php?id=423\&tp=a. Acesso em 25 abr. 2016.

Guillén, D. y Garcia, M. (2014). Expectativas desagregadas, credibilidade do Banco Central e Cadeias de Markov. Revista Brasileira de Economia, 68(2), 197-223.

Hann, J. de, y Kooi, W. (1997). What Really Matters: Conservativeness or Independence? Banca Nazionale del Lavoro Quarterly Review, 50(200), 23-38. Recuperado de: http://ojs.uniroma1. it/index.php/PSLQuarterlyReview/article/view/10569/10453. Acesso em: 03 maio 2016

Hamilton, J. D. (1994). Time Series Analysis. Princeton: Princeton University Press.

Hendry, D. F., Pagan, A. R. y Sargan, J. D. (1984). Dynamic specification. Handbook of Econometrics, 2, 1023-1100.

International Monetary Fund (FMI). (2014). Annual Report on Exchange Arrangements and Exchange Restrictions. Publication Services, Washington, Oct.

Jacomé, L. I. (2015). Central Banking in Latin America: From the gold standard to the golden years. IMF Working Paper No. 15/6. Recuperado de: https://www.imf.org/external/pubs/cat/longres.aspx?sk=42790.0. Acesso em 14 mar. 2016.

Kydland, F. y Prescott, E. (1977). Rules rather than discretion: The inconsistency of optimal plans. Journal of Political Economy, 85(3), 473-490.

Liddle P. C. y Pita J. J. (2011). Historia de la creación del Banco Central de la República Argentina. Ensayos Económicos, 1, 117-139.

Mishkin, F. S. (2012). Central Banking after the crisis. In: $16^{\circ}$ Annual Conference of the Central Bank of Chile, Santiago, nov.

Morandé, F. (2002). A decade of inflation targeting in Chile: Developments, lessons, and challenges. Central Bank of Chile. Santiago, Chile. Recuperado de: http://si2.bcentral.cl/public/ pdf/banca-central/pdf/v5/583_626Morande.pdf. Acesso em: 26 abr. 2016.

Mangano, G. (1998). Measuring CB autonomy: A tale of subjectivity and of its consequences. Oxford Economic Papers, 50, 468-492.

Oatley, T. (1999). Central Bank Independence and Inflation: Corporatism, Partisanship, and AIternative Indices of Central Bank Independence. Public Choice, 98, 399-413.

Orrego, F. (2007). Autonomía del Banco Central de Reserva del Perú: Una perspectiva histórica. Revista Moneda, 135, 16-22. Recuperado de: http://www.bcrp.gob.pe/docs/Publicaciones/ Revista-Moneda/Moneda-135/Revista-Moneda-135-04.pdf. Acesso em: 03 maio 2016.

Quispe, Z. y Rossini, R. (2010). Monetary policy during the global financial crisis of 2007-09: the case of Peru. BIS Papers, № 54. Recuperado de: http://papers.ssrn.com/sol3/papers.cfm?abstract_id $=1959828 \#$ page $=305$.

Reátegui, V. T. (2007). Independecia legal y efectiva del Banco Central de Reserva del Peru. Working Paper Series № 2007-012. Disponível em: http://www.bcrp.gob.pe/docs/Publicaciones/Documentos-de-Trabajo/2007/Working-Paper-12-2007.pdf. 
Rogoff, K. (1985). The Optimal Degree of Commitment to an Intermediate Monetary Target. Quarterly Journal of Economics, 100(4), 1169-1189.

Romer, C. D. y Romer, D. H. (2004). A New Measure of Monetary Shocks: Derivation and Implications. The American Economic Review, 94, 1055-1084.

Sims, C. A. (1980). Macroeconomics and Reality. Econometrica, 48(1), 1-48.

Sims, C. A. y Zha, T. A. (2002). Macroeconomic switching. Federal Reserve Bank of San Francisco Proceedings. No. Mar. 2002.

Sims, C. A. y Zha, T. A. (2004). MCMCMethod for Markov Mixture Simultaneous-Equation Models: A Note. FRB of Atlanta Working Paper No. 2004-15.

Souza. R. G. y Alves, A. F. (2010). Relação entre câmbio e preços no Brasil: aspectos teóricos e evidências empíricas. In: Encontro Nacional de Economia da ANPEC, 38, Salvador, 710 dez.

Walsh, C. (1995). Optimal Contracts for Central Bankers. American Economic Review, 85(1), 150-67.

\section{Apêndice A}

Quadro 1A - Síntese dos Estudos Empíricos Analisados

\begin{tabular}{|c|c|c|c|c|}
\hline Estudo & Período & Método & Objetivo & Resultados/Contribuições \\
\hline $\begin{array}{c}\text { Sims e Zha } \\
\text { (2004) }\end{array}$ & $\begin{array}{l}1959- \\
2003\end{array}$ & MS-VAR & $\begin{array}{c}\text { Fazer suposições e } \\
\text { identificar explici- } \\
\text { tações para isolar es- } \\
\text { timativas do compor- } \\
\text { tamento da política } \\
\text { monetária e seus } \\
\text { efeitos sobre a eco- } \\
\text { nomia. }\end{array}$ & $\begin{array}{l}\text { O modelo sugere que nem perturbações aditivas } \\
\text { a uma política monetária linear e nem alterações } \\
\text { nos coeficientes de função têm sido a fonte pri- } \\
\text { mária da ascensão e queda da inflação ao longo } \\
\text { do período da amostra. Em vez disso, uma polí- } \\
\text { tica monetária estável apresenta uma matriz de } \\
\text { mudança das grandes perturbações gerado o } \\
\text { padrão histórico. Um grande papel foi atribuído } \\
\text { aos tais "Choques do setor privado", seria útil con- } \\
\text { siderar um modelo que permite mais uma inter- } \\
\text { pretação mais detalhada destes choques. }\end{array}$ \\
\hline $\begin{array}{c}\text { Souza e Alves } \\
(2010)\end{array}$ & $\begin{array}{l}1999- \\
2009\end{array}$ & $\begin{array}{l}\text { Mecanismo de } \\
\text { Correção de Erros } \\
\text { (VEC), VAR e SVAR }\end{array}$ & $\begin{array}{l}\text { Analisar teórica e em- } \\
\text { piricamente a relação } \\
\text { entra e taxa de câm- } \\
\text { bio e preços no Brasil. }\end{array}$ & $\begin{array}{l}\text { O pass-through muito elevado devem-se ao } \\
\text { fato da mudança do regime cambial de fixo para } \\
\text { flexível, o apagão de energia elétrica em 2001, o } \\
\text { processo eleitoral em } 2002 \text { e a fatores externos } \\
\text { como o atentado ao World Trade Center e a crise. } \\
\text { No período mais estável da economia brasileira, } \\
\text { com crescimento produto do emprego, estabili- } \\
\text { dade de preços e uma tendência de apreciação } \\
\text { cambial, o grau de passagem cambial foi um } \\
\text { pouco menor. }\end{array}$ \\
\hline
\end{tabular}




\begin{tabular}{|c|c|c|c|c|}
\hline Estudo & Período & Método & Objetivo & Resultados/Contribuições \\
\hline $\begin{array}{c}\text { Couto e Fraga } \\
(2013)\end{array}$ & $\begin{array}{l}1999- \\
2000\end{array}$ & $\begin{array}{l}\text { Mecanismo de } \\
\text { Correção de Erros } \\
\text { (VEC) }\end{array}$ & $\begin{array}{l}\text { Analisar a relação en- } \\
\text { tre a taxa de câmbio } \\
\text { e preços no Brasil, no } \\
\text { longo prazo. }\end{array}$ & $\begin{array}{l}\text { A relação entre o pass-through da taxa câmbio } \\
\text { e os índices de preços no longo prazo é esta- } \\
\text { tisticamente significante ou o repasse é quase } \\
\text { completo. }\end{array}$ \\
\hline $\begin{array}{l}\text { Guillén e Gar- } \\
\text { cia (2014) }\end{array}$ & $\begin{array}{l}2002- \\
2007\end{array}$ & $\begin{array}{l}\text { Cadeias de Markov } \\
\text { matrizes de tran- } \\
\text { sição }\end{array}$ & $\begin{array}{c}\text { Propor um novo mé- } \\
\text { todo para estimar a } \\
\text { credibilidade de um } \\
\text { banco central utili- } \\
\text { zando expectativas } \\
\text { desagregadas entre } \\
\text { os agentes da econo- } \\
\text { mia brasileira. }\end{array}$ & $\begin{array}{l}\text { Se os agentes mudarem os seus comportamen- } \\
\text { tos aleatoriamente, isto indicará que há credibi- } \\
\text { lidade. No entanto, se houver persistência nos } \\
\text { estados, há desconfiança da verdadeira aversão } \\
\text { do banco central à inflação, fazendo com que } \\
\text { alguns agentes se mantenham otimistas e ou- } \\
\text { tros, pessimistas. A hipótese subjacente é que } \\
\text { a fonte de heterogeneidade advém de descon- } \\
\text { fiança com relação à verdadeira aversão do Ban- } \\
\text { co Central à inflação. Os resultados encontrados } \\
\text { sugerem que agentes otimistas e pessimistas se } \\
\text { comportam de forma semelhante, isto é, as tra- } \\
\text { jetórias temporais dos otimistas e dos pessimis- } \\
\text { tas é semelhante. }\end{array}$ \\
\hline
\end{tabular}

Fonte: elaboração própria.

Tabela A1. Teste de Causalidade de Granger para os três modelos com duas defasagens.

\begin{tabular}{|c|c|c|}
\hline Hipótese Nula & Estatística F & Prob. \\
\hline \multicolumn{3}{|l|}{ Modelo 1} \\
\hline$\Delta$ Índice de Taxa de câmbio não Granjer causa $\Delta$ Índice de Preços & 4,28315 & 0,0153 \\
\hline LÍndice de Preços não Granjer causa $\Delta$ Índice de Taxa de Câmbio & 2,55395 & 0,0807 \\
\hline$\Delta$ Taxa de Juros não Granjer causa $\Delta$ Índice de Preços & 3,94942 & 0,021 \\
\hline$\Delta$ Índice de Preços não Granjer causa $\Delta$ Taxa de Juros & 4,49225 & 0,0125 \\
\hline$\Delta$ Taxa de Juros não Granjer causa $\Delta$ Índice de Taxa de Câmbio & 0,29175 & 0,7473 \\
\hline$\Delta$ Índice de Taxa de câmbio não Granjer causa $\Delta$ Taxa de Juros & 0,52086 & 0,5949 \\
\hline \multicolumn{3}{|l|}{ Modelo 2} \\
\hline $\Delta$ Índice de Taxa de câmbio não Granjer causa $\Delta$ Índice de Preços & 3,11490 & 0,0469 \\
\hline$\Delta$ Índice de Preços não Granjer causa $\Delta$ Índice de Taxa de Câmbio & 1,76278 & 0,1747 \\
\hline$\Delta$ Taxa de Juros não Granjer causa $\Delta$ Índice de Preços & 1,27675 & 0,2816 \\
\hline$\Delta$ Índice de Preços não Granjer causa $\Delta$ Taxa de Juros & 2,10825 & 0,1246 \\
\hline$\Delta$ Taxa de Juros não Granjer causa $\Delta$ Índice de Taxa de Câmbio & 0,01503 & 0,9851 \\
\hline$\Delta$ Índice de Taxa de câmbio não Granjer causa $\Delta$ Taxa de Juros & 2,07371 & 0,1289 \\
\hline
\end{tabular}


122 Análise comparada da estrutura e desempenho dos bancos centrais de três países da América Latina doi: http://dx.doi.org/10.21789/24222704.1277

\begin{tabular}{|c|c|c|}
\hline Hipótese Nula & Estatística F & Prob. \\
\hline \multicolumn{3}{|l|}{ Modelo 3} \\
\hline$\Delta$ Índice de Taxa de câmbio não Granjer causa $\Delta$ Índice de Preços & 2,25421 & 0,108 \\
\hline$\Delta$ Í́ndice de Preços não Granjer causa $\Delta$ Índice de Taxa de Câmbio & 1,14611 & 0,3203 \\
\hline$\Delta$ Taxa de Juros não Granjer causa $\Delta$ Índice de Preços & 0,52356 & 0,5933 \\
\hline$\Delta$ Índice de Preços não Granjer causa $\Delta$ Taxa de Juros & 4,75671 & 0,0098 \\
\hline$\Delta$ Taxa de Juros não Granjer causa $\Delta$ Í́ndice de Taxa de Câmbio & 3,91558 & 0,0217 \\
\hline$\Delta$ Índice de Taxa de câmbio não Granjer causa $\Delta$ Taxa de Juros & 0,83853 & 0,4341 \\
\hline
\end{tabular}

Fonte: elaboração própria. 